\title{
Correcting Shape and Size Using Temporary Filler after Breast Augmentation with Silicone Implants
}

Jun Ho Shin, Jeong Seok Suh, Si Gang Yang

UP2C Plastic Surgery Clinic, Seoul, Korea

No potential conflict of interest relevant to this article was reported.

\begin{abstract}
Breast contour deformities, lack of volume and asymmetry are common confronted problems after breast augmentation with implants. These problems can be corrected by using temporary fillers or autologous fat grafts. The purpose of this study was to introduce our experience using long lasting temporary filler (Aquafilling ${ }^{\circledR}$ ) for the correction of unfavorable results after breast augmentation with silicone implants. Two nonpregnant, non-breastfeeding women unsatisfied with previous breast augmentation with silicone implants were recruited for this study. All procedures were performed under local anesthesia with sedation. Efficacy and safety assessments were carried out at follow-up visits (1, 3, and 6 months). The study showed that Aquafilling could provide satisfactory improvement in breast shape and volume. Also it showed that the corrected volume and shape were lasting without affecting the breasts' original volume. Patients reported high satisfaction as Aquafilling ${ }^{\circledR}$ was generally well tolerated with no inflammatory reactions or serious adverse events. We recommend that Aquafilling ${ }^{\circledR}$ as a new option for the correction of minor problems after breast augmentation surgery with implants. However, further follow-up studies are required to observe long-term results.
\end{abstract}

Keywords Breast implants, Mammaplasty, Silicones

\section{INTRODUCTION}

Breast augmentation is a major plastic surgery used to enhance the aesthetics of a woman's body shape, which generally increases a woman's self-esteem [1]. Although breast implants are commonly used for breast augmentation, the characteristics of the surgery, which involve an implant of standard form and size, make it difficult to revise the results with other than repeated surgery.

Even though revision using an autologous fat graft has been attempted, implanted fat absorption and a sacrificed donor site are disadvantages, requiring repetitive procedures [2,3]. There are few

Received: Jul 2, 2015 Revised: Jul 31, 2015 Accepted: Aug 4, 2015 Correspondence: Jun Ho Shin UP2C Plastic Surgery Clinic, 15F, Urban Bench Building, 325 Teheran-ro, Gangnam-gu, Seoul 06151, Korea. E-mail: shin1272@up2c.co.kr

Copyright $\odot 2015$ The Korean Society for Aesthetic Plastic Surgery.

This is an Open Access article distributed under the terms of the Creative Commons Attribution Non-Commercial License (http://creativecommons.org/licenses/by-nc/3.0/) which permits unrestricted non-commercial use, distribution, and reproduction in any medium, provided the original work is properly cited. www.e-aaps.org alternative methods for a patient who is not satisfied with the size and form of the implant but does not want repeated surgery to remove the existing implant and re-implant a different one, or has experienced difficulty with an autologous fat graft due to a thin body [2]. Therefore, the authors of this paper report that relatively satisfactory results using a filler to improve the size and shape of the implant that has already been inserted into the breast.

\section{CASE REPORTS}

\section{Case 1}

The patient had a $250 \mathrm{~mL}$, smooth, round silicone implant inserted under the pectoralis major muscle using a transaxillary approach 5 years ago. She did not experience complications such as capsular contracture but wanted to increased volume in the medial, lower pole of the breast (Fig. 1).

The patient did not want a repeated surgery to replace the implant but asked for partial correction with a filler due to concerns about donor site morbidity. 

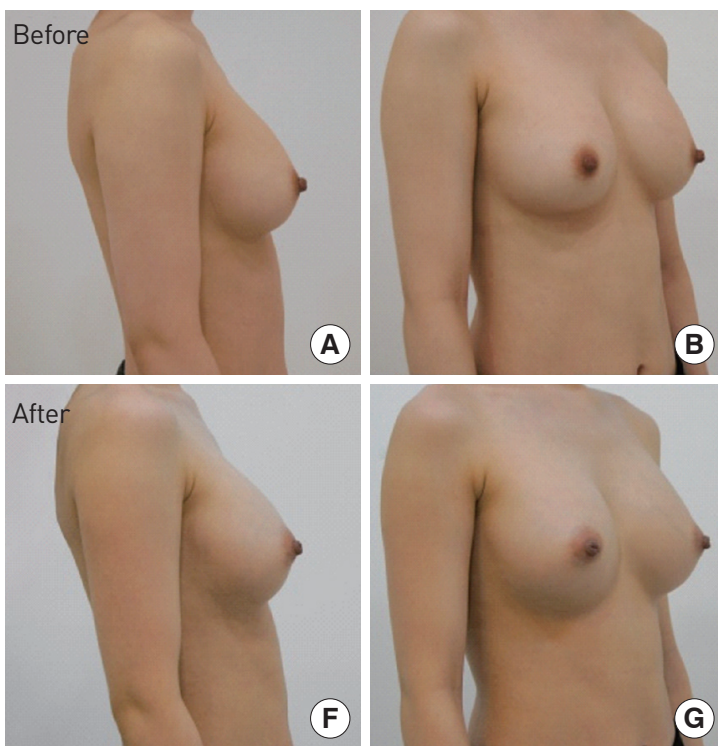

B
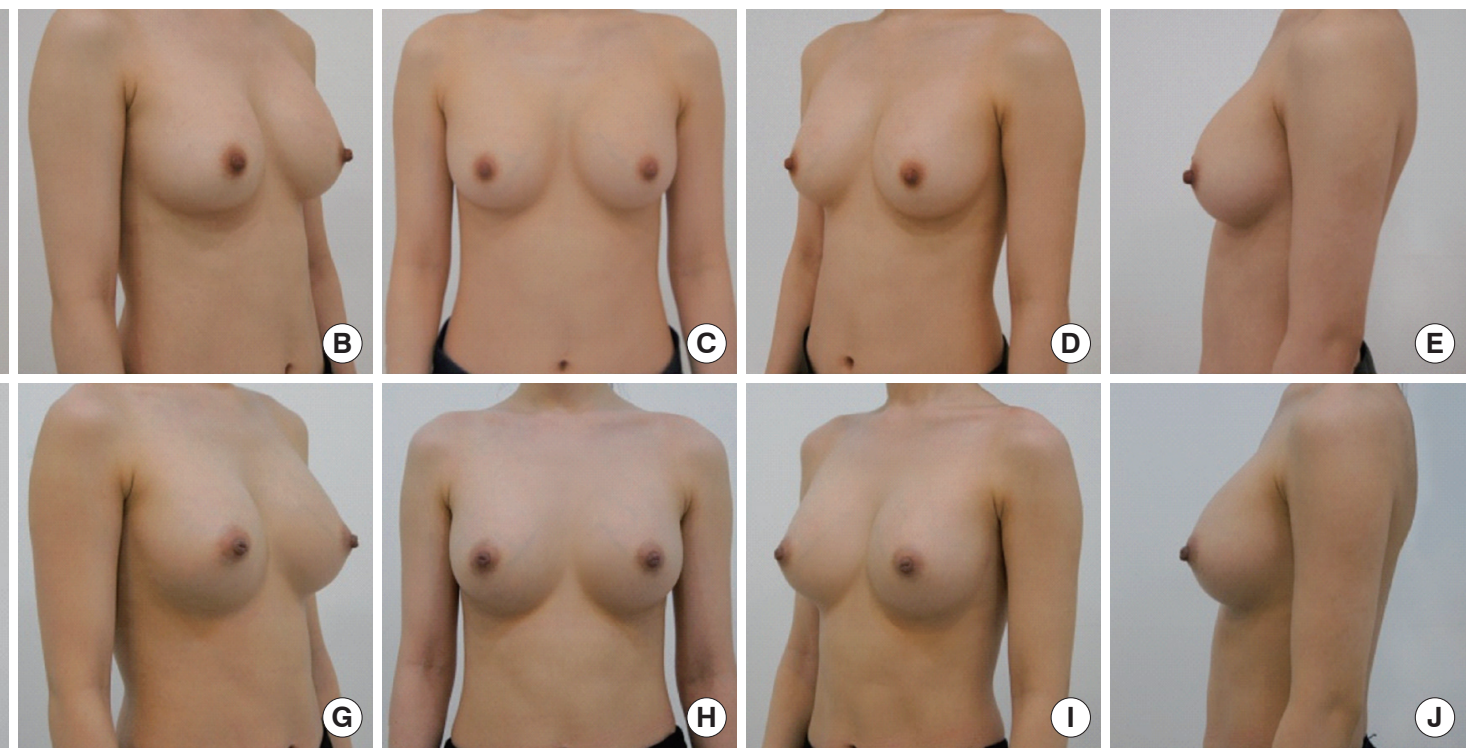

Fig. 1. Case 1. (A-E) Preoperative views; (F-J) postoperative views at 6 months.
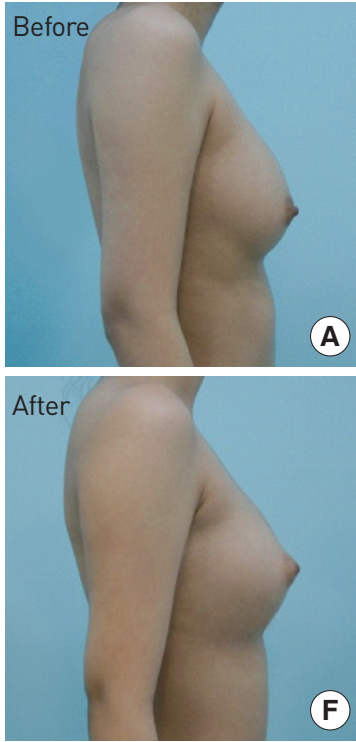

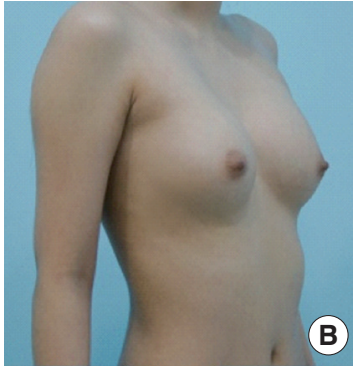

(B)

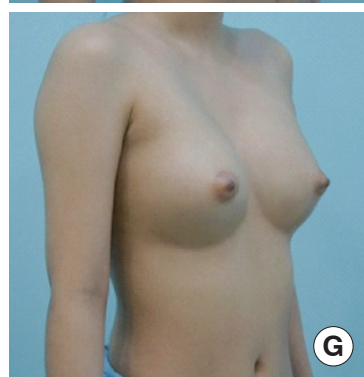

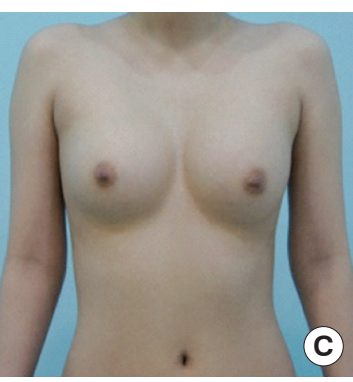
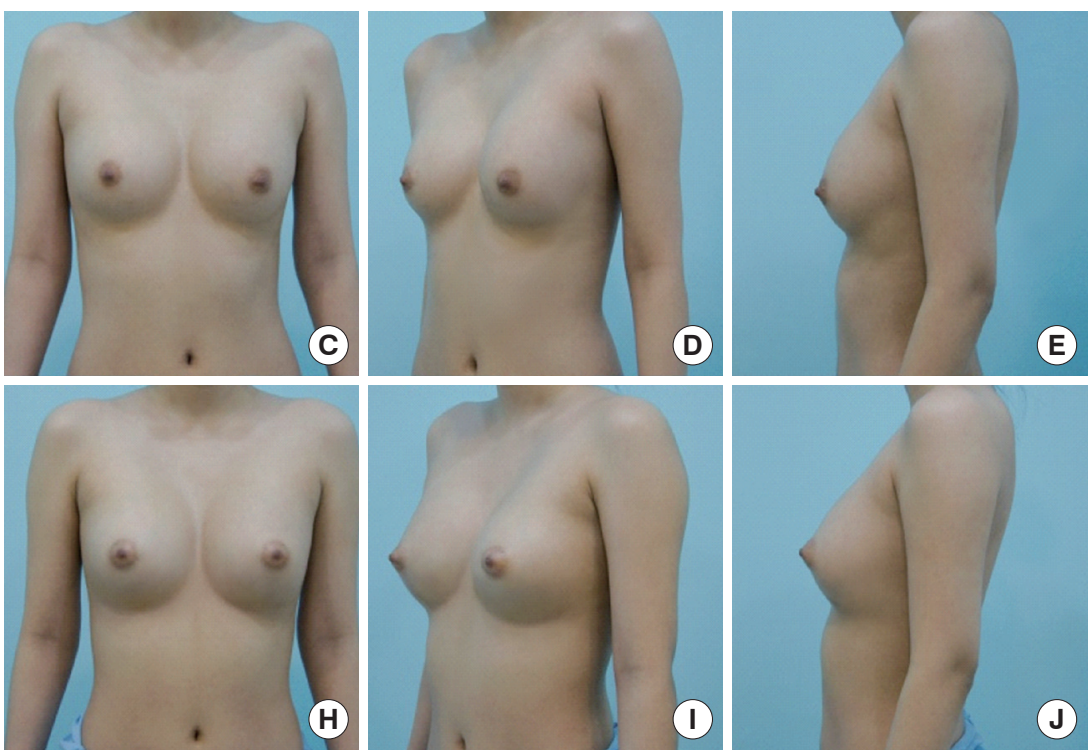

Fig. 2. Case 2. (A-E) Preoperative views; (F-J) postoperative views at 6 months.

\section{Operative procedures}

Before the surgery, the parts for filling were marked in advance with the patient in the standing position. Under sedation anesthesia, an incision of approximately $3 \mathrm{~mm}$ was made on the lateral side of the inframammary fold and using an 11-ga cannula with a blunt edge; approximately $10 \mathrm{~mL}$ tumescent solution was injected slowly into the space reserved for the filler on each side, with extra care taken so as not to damage the capsule of the breast implant. After 5 minutes, using the same 11-ga cannula, $30 \mathrm{~mL}$ filler was slowly injected into the marked body part. The filler should be injected while moving the cannula slowly so as not to damage the capsule of the breast implant. By manipulating the operating table, the patient was placed in a sitting position. After comparing the sizes of both breasts, the smaller regions were marked. Then, the operating table was manipulated into a position convenient for filler injection, and an additional 29 and $11 \mathrm{~mL}$ filler were injected into the right and left sides, respectively. The patient was put in a sitting position again, and both breasts were compared for final confirmation. The incision was sutured with 6-0 nylon, completing the surgery. 


\section{Results}

Six months after surgery, the patient is satisfied with the augmentation of the inner side and lower parts of the breasts; a follow-up schedule is planned for this patient.

\section{Case 2}

The patient had a $230 \mathrm{~mL}$ silicone implant inserted under the pectoralis major muscle using a transaxillary approach 1.5 years ago. Although she did not have special complications such as capsular contracture, she sought help because of a general lack of volume and asymmetry for both breasts (Fig. 2). She asked for a simple surgery procedure to replace the implant or insert a fat graft. A filler injection was recommended and accepted.

\section{Operation procedures}

Ninety-five $\mathrm{mL}$ filler were injected evenly into the right breast, and $65 \mathrm{~mL}$ filler were injected evenly into the left breast using the same procedure described above.

\section{Results}

Six months after surgery, the symmetry of the breasts was improved, and the patient is generally satisfied with the results; a follow-up schedule is planned for this patient.

\section{DISCUSSION}

Fillers have been mainly used for aesthetic purposes to restore sagging parts of face or eliminate wrinkles, depending on the particular ingredients. While surgeons can manipulate the form and volume of the filler for the desired parts of the body, it is possible to reconstruct breasts of patients who previously underwent breast augmentation surgery using implants by injecting an adequate amount of filler in the space between the implant and the skin for a more satisfactory size and form.
By injecting an adequate amount of filler, the authors tried to correct or complement the breasts of patients who want the outline of their breasts corrected after breast augmentation surgery using implants. Among the various fillers available, we used Aquafilling ${ }^{\circledR}$ filler, which is composed of $98 \%$ water and $2 \%$ copolyamide. Since it is homogeneous and soft, this hyaluronic acid (HA) monophasic filler has excellent lifting capacity and viscoelasticity compared to an HA biphasic filler or calcium filler, and thus can modify the form instantly through molding as well as properly maintain a natural form in a narrow space between the implant and the skin [4]. We also considered that a mid-to-long-term filler can be expected to last several years. Therefore, a filler can be considered an alternative method for breast aesthetic surgery in patients who want to eliminate implants but desire breasts of a natural form and proper size. Fillers can also be used in patients who do not want implant surgery and have experienced difficulty with an autologous fat graft due to a thin body.

\section{PATIENT CONSENT}

Patients provided written consent for the use of their images.

\section{REFERENCES}

1. Siebert T, Chaput B, Vaysse C, et al. The latest information on Macrolane: its indications and restrictions. Ann Chir Plast Esthet 2014;59:e1e11.

2. Li FC, Chen B, Cheng L. Breast augmentation with autologous fat injection: a report of 105 cases. Ann Plast Surg 2014;73 Suppl 1:S37-42.

3. Hedén P, Sellman G, von Wachenfeldt M, et al. Body shaping and volume restoration: the role of hyaluronic acid. Aesthetic Plast Surg 2009; 33:274-82.

4. Zlenko A, Usov S, Vasylenko I. Efficacy and tolerability (safety) of hydrophilic gel in breast plastic surgery. Prime 2012;2:56-7. 